\title{
Derivative Spectrophotometric Methods for the Analysis and Stability Studies of Ranolazine in Bulk and Dosage Forms
}

Noon A. A. Kamil ${ }^{1}$

ORCID: 0000-0002-9874-386X

Shaza W. Shantier ${ }^{2 *}$

ORCID: 0000-0002-2543-0248

Elrasheed A. Gadkariem ${ }^{2}$

ORCID: 0000-0002-7099-0068 ${ }^{1}$ Fatima College of Health Sciences,
Pharmacy department, UAE

${ }^{2}$ Department of Pharmaceutical Chemistry, Faculty of Pharmacy, University of Khartoum, Sudan

Corresponding author:

Shaza W. Shantier

Department of Pharmaceutical Chemistry, Faculty of Pharmacy, University of Khartoum, Sudan

E-mail: sshantier@yahoo.com

\section{DOI: 10.52794/hujpharm.1029049}

\section{ABSTRACT}

The present study was aimed to develop simple and accurate derivative spectrophotometric methods ( $\left({ }^{1} \mathrm{D}\right.$ and $\left.{ }^{2} \mathrm{D}\right)$ for the assay and stability studies of Ranolazine (RAN) in bulk and dosage forms. The methods were based on differentiating the original UV spectrum of RAN solution in methanol to generate the first and second derivative spectra which were measured at $278 \mathrm{~nm}$ and $283 \mathrm{~nm}$, respectively. The developed methods were then validated as per ICH guidelines and applied for the stability studies. Beer's law was found to be valid over the concentration range $100-600 \mu \mathrm{g} / \mathrm{ml}$ with correlation coefficient (r) not less than 0.999 . The obtained limit of detection (LOD) and limit of quantification (LOQ) reflected the sensitivity of the methods $(24.0 \mu \mathrm{g} / \mathrm{ml}$ and $73.0 \mu \mathrm{g} / \mathrm{ml}, 17.8 \mu \mathrm{g} / \mathrm{ml}$ and $53.6 \mu \mathrm{g} /$ $\mathrm{ml}$, for ${ }^{1} \mathrm{D}$ and ${ }^{2} \mathrm{D}$, respectively). Good results were also obtained from the assay of RAN tablets $(98.6 \pm 2.3 \%, n=3)$. Studying the stability behavior of RAN using the developed methods reflects its instability under alkaline conditions following the first-order kinetics. The statistical validation at a 95\% confidence level proves the sensitivity, precision, accuracy, and stability-indicating properties of the developed methods.

Keywords: Ranolazine, Spectrophotometry, ICH standards, Stability, Kinetics. 


\section{INTRODUCTION}

The need to develop a stability-indicating method using stress degradation has been recommended by International Conference of Harmonization ${ }^{1}$. In practice, the effects of $\mathrm{pH}$ and temperature changes on drug stabilityare often used in such studies. The results of such studies are of great importance in the estimation of drug shelf life and the effect of degradation products on decreasing efficacy and causing toxicity. They may also serve as guidesfor better drug design, drug formulation and drug analysis.

The stability of a pharmaceutical product is defined as the capability of the product to retain its efficacy, properties and characteristics throughout its shelf life $^{2}$. One of the most important types of stability is chemical stability which includes hydrolysis. Amides are generally more stable to hydrolysis than esters. In general, the rate of hydroxyl ion- catalyzed reaction of amides is greater than the rate of protoncatalyzed hydrolysis ${ }^{3}$.

Ranolazine (RAN, Figure 1) is an amide containing compound, piperazine derivative with anti-anginal and potential antineoplastic activities. The IUPAC name is $\mathrm{N}$-(2,6-dimethylphenyl)-2-[4-[2-hydroxy3-(2-methoxyphenoxy)propyl]piperazin-1-yl] acetamide. It has the molecular formula $\left(\mathrm{C}_{24} \mathrm{H}_{33} \mathrm{~N}_{3} \mathrm{O}_{4}\right)^{4}$. Although its relationship to angina symptoms is uncertain, RAN can inhibit the inactivating component of the sodium current (I $(\mathrm{Na})$ ) at therapeutic levels. It also inhibits the rapid inward rectifying current (I $(\mathrm{Kr})$ ), thereby prolonging the ventricular action potential ${ }^{5}$.

Although literature revealed different methods (chromatographic and spectroscopic methods) for the assay of RAN ${ }^{6-22}$, neither official pharmacopeias' methods nor stability studies utilizing spectrophotometric methods are available. Although the UV spectrophotometric methods might lack selectivity, the present method was found to be superior on the reported methods in terms of simplicity, cost-effectiveness and stability indication. Therefore, the aim of the present work was to develop simple and accurate derivative spectrophotometric methods for the analysis and stability studies of RAN in bulk and dosage forms.

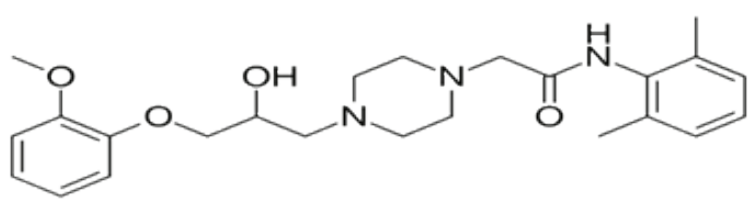

Figure 1. Chemical structure of Ranolazine

\section{MATERIALS and METHODS}

\section{Apparatus}

UV spectrophotometric studies were carried out on Shimatzu UV- 1800EN240V, double beam, (Kyoto, Japan). The operating conditions were as follows:

- Wavelength range: 240-400 nm.

- Scan speed: Medium, $0.2 \mathrm{~nm} / \mathrm{s}$.

Sensitive balance: Kern ALS 120-4, Germany

\section{Reference standard and sample}

RAN reference standard was purchased from Lab CO in UAE (98\%). RAN tablets: Ranexa 375 mg prolonged release tabs were purchased from UAE.

\section{Chemicals}

Methanol Lobalchemie, India. Sodium hydroxide: BDH, Poole, England.Hydrochloric acid: BDH, Poole, England

\section{Preparation of stock solutions}

\section{Standard stock solution}

Standard stock solution was prepared by dissolving $0.1 \mathrm{~g}$ of RAN standard in $100 \mathrm{ml}$ methanol (Solution A; $1000 \mu \mathrm{g} / \mathrm{ml})$.

\section{Sample stock solution}

Ten tablets of Ranexa (RAN 375 mg) were accurately weighed and grinded. An equivalent amount containing 0.1g RAN was weighed and dissolved in $20 \mathrm{ml}$ methanol and transferred into $100 \mathrm{ml}$ volumetric flask. The volume was completed to mark with methanol. The solution was sonicated for $10 \mathrm{~min}$ and filtered (Solution B; $1000 \mu \mathrm{g} / \mathrm{ml}$ ). 


\section{Method validation}

\section{Linearity}

Serial dilutions were made from solution A by transferring accurately measured volumes $(1-6 \mathrm{ml})$ into a set of $10 \mathrm{ml}$ volumetric flasks. The volumes were then completed to mark with the solvent (methanol), the ${ }^{1} \mathrm{D}$ and ${ }^{2} \mathrm{D}$ order derivative spectra were recorded over the range $240-400 \mathrm{~nm}$. The procedure was repeated three times. The mean absorbance values were plotted against concentration to construct the calibration curve.

Limits of detection and quantification were determined from the calibration curve using adopted formulae ${ }^{23}$ :

$\mathrm{LOD}=3.3 \mathrm{SB} /$ Slope

$\mathrm{LOQ}=10 \mathrm{SB} /$ Slope

Where SB is the standard deviation calculated from the regression analysis data.

\section{Content uniformity}

Three $\mathrm{mL}$ of solution $\mathrm{B}$ was transferred into $10 \mathrm{~mL}$ volumetric flask. The volume was then completed to mark with the solvent (methanol), and the absorbance values were recorded over the range $240-400$ $\mathrm{nm}$. The procedure was repeated three times. The content uniformity of the tablet solutions was then evaluated by the direct comparison of sample/standard absorbance values.

\section{Precision}

Serial dilutions from solution A were done as under linearity to obtain concentrations of $100 \mu \mathrm{g} /$ $\mathrm{ml}, 200 \mu \mathrm{g} / \mathrm{ml}$ and $300 \mu \mathrm{g} / \mathrm{ml}$. These solutions were scanned using the derivative modes $\left({ }^{1} \mathrm{D}\right.$ and $\left.{ }^{2} \mathrm{D}\right)$ three times within the same day (inter-day) and at three consecutive days (intra-day). The results obtained were used to evaluate the precision of the developed method in terms of relative standard deviation values (RSD \%).

\section{Recovery percentage}

Recovery studies were carried out by spiking sample of known concentration with standard solution. The recovery percentage was then determined using the following equation ${ }^{24}$ :
$\%$ recovery $=\left(C_{s}-C_{u}\right) / C_{A} \times 100$

Where:

$\mathrm{C}_{\mathrm{s}}=$ concentration of spiked samples; $\mathrm{C}_{u}=$ concentration of unspiked samples; $C_{A}=$ concentration of analyte added to the test sample

\section{Stability studies}

Effect of alkali and acid on the stability of RAN solution

Aliquots of solution A $(2 \mathrm{~mL})$ were transferred to four stoppered glass tubes then $1 \mathrm{ml}$ of $0.05 \mathrm{M} \mathrm{NaOH}$ was added to each tube. The volumes were then completed to mark with methanol. The first and second derivative spectra of the first tube were recorded at zero time. The other three tubes were heated in a boiling water bath at 15 minutes heating time interval. The solutions were then cooled and the effect of the alkali on the degradation of RAN was monitored using the developed methods.

The same procedure was repeated adding $1 \mathrm{~mL}$ of $1 \mathrm{M}$ $\mathrm{HCl}$ instead of $\mathrm{NaOH}$ to study the effect of acid on RAN stability.

\section{Light effect}

RAN standard methanolic solution $(40 \mu \mathrm{g} / \mathrm{ml})$ was prepared and placed in transparent glass tubes. The solutions were then subjected to direct sunlight during mid-day time for 6 hours. The photo-degradation was then monitored using the developed methods.

\section{RESULTS and DISCUSSION}

Discovery of new drugs, their synthesis and manufacturing in suitable pharmaceutical forms, is a highly expensive process. Consequently, the development of accurate and precise methods is important for their analysis to ensure their quality.

For any drug stability studies, a validated stabilityindicating method that can distinguish the active ingredient from its degradation products is the first and major requirement by the International Conference on Harmonization (ICH) ${ }^{1}$. Direct spectrophotometric methods (zero-order) are widely used in pharmaceutical analysis although they lack selectivity and stability-indicating properties. Prior to the develop- 
ment of derivative spectroscopy, chromatography was the most frequent used method for stability studies. Chromatographic techniques have been advanced by introducing various types of columns and detectors which improve the selectivity and efficiency of the procedure and its application in structural elucidation. However, these techniques are still expensive, time-consuming and require sophisticated skills which may not be available in each analytical laboratory especially in the developing countries.

The development of derivative spectroscopy provided simple and accurate tool for the analysis and stability studies of different pharmaceutical dosage forms ${ }^{25-28}$

Derivative spectrophotometry is based on the mathematical differentiation of spectral curve into a derivative (first- or higher derivatives). This technique usually improves resolution bands, eliminates the influence of background or matrix and provides more defined fingerprints than traditional ordinary or direct absorbance spectra, since it enhances the detectability of minor spectral features ${ }^{29}$.

Thus, our aim in the present work was to develop accurate derivative spectrophotometric methods for the analysis of RAN which will be also applied for its stability studies under stress conditions according to the ICH guidelines. The developed first and second derivative modes $\left({ }^{1} \mathrm{D}\right.$ and $\left.{ }^{2} \mathrm{D}\right)$ were successfully applied for the stability studies and quantification of the degradation products. However, the ${ }^{2} \mathrm{D}$ resulted in better resolution between the drug and its degradation products peaks at longer and shorter wavelengths than the parent drug, which can also be applied as an identification tool. This is also come in favor to the reported chromatographic methods by Gade et al., 2011; Khedkar et al., 2015 in terms of simplicity, accuracy and time saving ${ }^{9,10}$.

The zero-order derivative spectrum of RAN shows absorption maximum at $273 \mathrm{~nm}$ (Figure 2). Since derivatization of normal spectrum gives rise to reduction of band width, sharper peaks were achieved on the first and second order derivative spectra of RAN showing an absorption maximum at $278 \mathrm{~nm}$ and 283 $\mathrm{nm}$ (Figures 3 and 4).

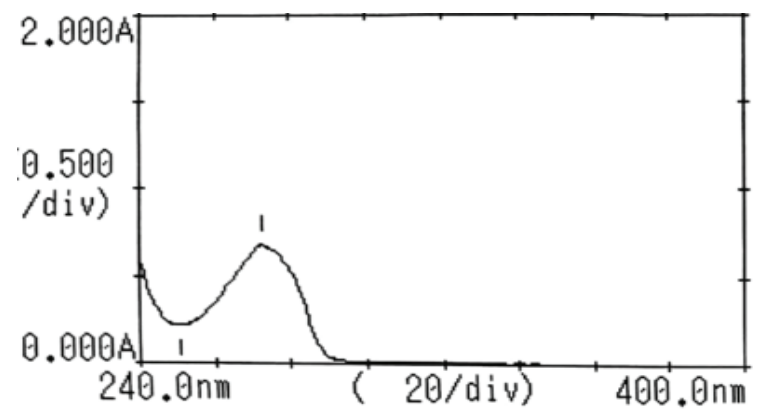

Figure 2. UV spectrum of RAN solution $(100 \mu \mathrm{g} / \mathrm{ml} ; 273 \mathrm{~nm})$

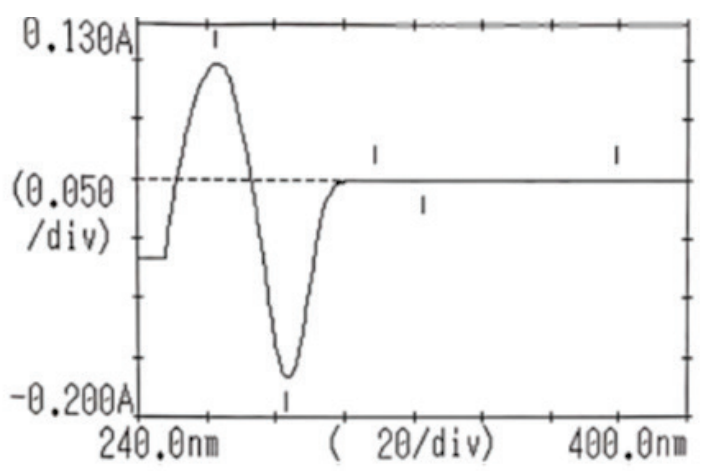

Figure 3. First derivative spectrum of RAN solution $(400 \mu \mathrm{g} / \mathrm{ml} ; 283 \mathrm{~nm})$

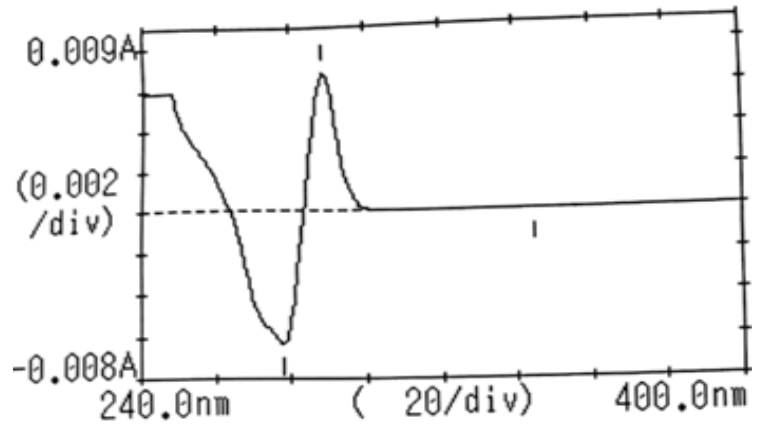

Figure 4. Second derivative spectrum of RAN solution (100 $\mu \mathrm{g} / \mathrm{ml} ; 278 \mathrm{~nm})$

\section{Linearity}

The constructed calibration curves for the ${ }^{1} \mathrm{D}$ and ${ }^{2} \mathrm{D}$ modes was found to obey Beer's law in a concentration range $100-600 \mu \mathrm{g} / \mathrm{ml}$ with a good correlation coefficient (not less than 0.999). The regression analysis data was calculated at $95 \%$ confidence level for $\mathrm{n}-2$ degrees of freedom using the following formula $^{23}$ : 
$y=\left(b \pm t_{b}\right) x+(a \pm t s a)$

Results obtained for linearity data of the developed method was summarized in table 1 , which reflected the sensitivity and consistency of the constructed curve.

\section{Assay and Validation}

The developed methods were applied for the drug uniformity testing in RAN tablets. Good assay results were obtained using ${ }^{1} \mathrm{D}$ and ${ }^{2} \mathrm{D}$ modes $(101.4 \pm$ $1.34 \% ; 98.6 \pm 2.3 \%, \mathrm{n}=3$, respectively). The validity of the methods was assessed by statistical evaluation of the results obtained using the following formula ${ }^{30}$ :

$\mathrm{t}=\mathrm{X}^{\prime}-\mu \sqrt{ } \mathrm{N} / \mathrm{S}$

where $\mathrm{X}^{`}=$ content $\%$ mean at $95 \%$ confidence level $(99.5 \%), \mu=$ true mean $\mathrm{N}=$ number of measurements, $\mathrm{S}=$ standard deviation .
As the calculated t-value for ${ }^{1} \mathrm{D}$ and ${ }^{2} \mathrm{D}(2.095$ and 1.596 , respectively) is less than the tabulated one (12.706), this reflects there is no significant difference between the developed method and the true mean value.

\section{Precision and accuracy}

The precision results showed acceptable RSD\% values ranging between $0.00-2.3 \%$ for inter-day and intra-day precisions, respectively. These low values (less than 2\%) reflected the precision of the developed methods.

The accuracy of the developed method and freedom of interference by tablet excipients were confirmed by the good results obtained from recovery testing $(96.5 \pm 3.05 \%, n=3)$ (Table 2)

Table 1. Regression analysis data of the developed method $(n=3)$

\begin{tabular}{ccc}
\hline Parameter & ${ }^{1} \mathbf{D}$ & $27 \mathrm{D}$ \\
\hline$\lambda_{\text {max }}$ & $283 \mathrm{~nm}$ & $100-600 \mu \mathrm{gg} / \mathrm{ml}$ \\
Concentration range & $100-600 \mu \mathrm{g} / \mathrm{ml}$ & $5.6 \times 10^{-5} \pm 1.13 \times 10^{-5}$ \\
Slope \pm tsb* & $1.0 \times 10^{-4} \pm 2.24 \times 10^{-5}$ & $-5.3 \times 10^{-4} \pm 8.2 \times 10^{-3}$ \\
Intercept \pm tsa** & $4.0 \times 10^{-3} \pm 1.8 \times 10^{-2}$ & $17.8 \mu \mathrm{g} / \mathrm{ml}$ \\
LOD & 24.0 & $53.6 \mu \mathrm{g} / \mathrm{ml}$ \\
LOQ & 73.0 & 0.999
\end{tabular}

*Standard error of slope at 95\% confidence level for (n-2) degrees of freedom, **Standard error of intercept at $95 \%$ confidence level for ( $\mathrm{n}-2)$ degrees of freedom

Table 2. Results of the studied validation parameters $\left({ }^{1} \mathrm{D},{ }^{2} \mathrm{D}\right)$

\begin{tabular}{lcccc}
\multicolumn{1}{c}{ Parameter } & Experiment 1 & Experiment 2 & Experiment 3 & Results \\
\hline $\begin{array}{l}\text { Inter-day precision } \\
(100-300 \mu \mathrm{g} / \mathrm{ml})\end{array}$ & $0.005-0.018$ & $0.005-0.018$ & $0.005-0.018$ & $\mathrm{RSD} \%=0$ \\
$\begin{array}{l}\text { Intra-day precision } \\
(100-300 \mu \mathrm{g} / \mathrm{ml})\end{array}$ & $0.005-0.018$ & $0.005-0.018$ & $0.005-0.017$ & $\mathrm{RSD} \%=2.3$ \\
Recovery $\%(300 \mu \mathrm{g} / \mathrm{ml})$ & 94.7 & 94.7 & 100.0 & $\mathrm{Mean} \pm \mathrm{SD}$ \\
& & & 101.3 & $96.50 \pm 3.05 \%$ \\
Content uniformity\% & 100.0 & 102.5 & Mean $\pm \mathrm{SD}$ & $101.40 \pm 1.34$ \\
\hline
\end{tabular}




\section{Stability studies}

Effect of alkali on the stability of RAN solution

Different $\mathrm{NaOH}$ concentrations with different heating time intervals were studied. $0.05 \mathrm{M} \mathrm{NaOH}$ with 15 minutes heating time interval was found appropriate and selected among the other concentrations for the further studies as it gave the best correlation coefficient.

The ${ }^{1} \mathrm{D}$ and ${ }^{2} \mathrm{D}$ spectra of RAN solution treated with $0.05 \mathrm{M} \mathrm{NaOH}$ showed subsequent decrease in its peak and concentration (Figures 5 and 6). It was unveiled from the ${ }^{1} \mathrm{D}$ and ${ }^{2} \mathrm{D}$ spectra that the parent peaks; at $283 \mathrm{~nm}$ and $278 \mathrm{~nm}$, respectively; are decreased in concentration and changed in shape $\left({ }^{2} \mathrm{D}\right)$ with the appearance of degradation products at longer and shorter wavelengths $(220 \mathrm{~nm}, 300 \mathrm{~nm}$ and $311 \mathrm{~nm}$ ). The $\log \%$ remained drug (Table 3 ) was obtained as follows:

Plotting the $\log \%$ values vs time revealed that the degradation rate follows first order kinetic (Figure 7). The degradation rate was found to be $\left[\mathrm{OH}^{-}\right]$dependent, suggesting that the $\mathrm{OH}^{-}$is playing the role of nucleophile (intermolecular hydrolysis) to give the proposed degradation process shown in Scheme 1.

Testing the effect of hydrochloric acid revealed no change in RAN spectra and concentration even at high temperatures. However, further studies are recommended to obtain the $\mathrm{pH}$ profile of RAN in addition to the effect of different temperatures on its stability.

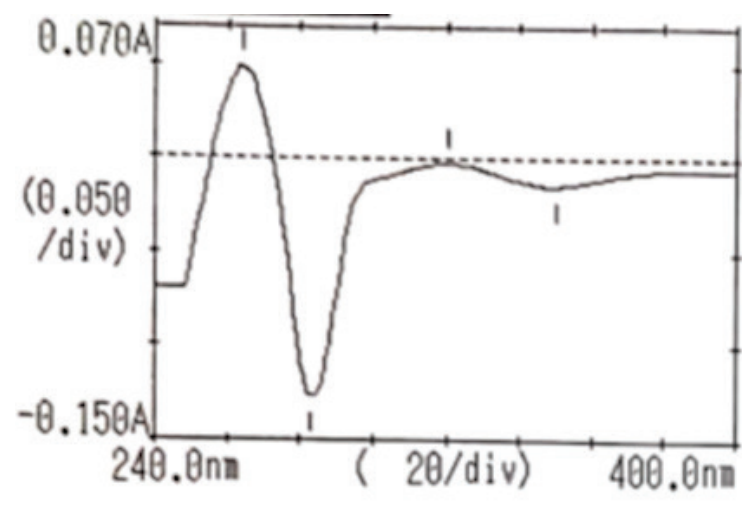

Figure 5. First derivative spectrum for alkali-treated RAN (30 minutes heating, parent drug at $283 \mathrm{~nm}$, degradation product at $311 \mathrm{~nm}$ )

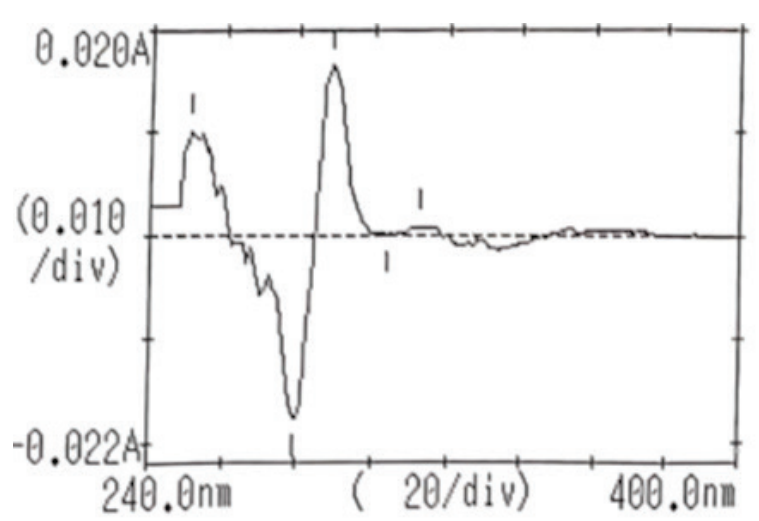

Figure 6. Second derivative spectrum for alkali-treated RAN (30 minutes heating, parent drug at $278 \mathrm{~nm}$, degradation products at $220 \mathrm{~nm}$ and $311 \mathrm{~nm}$ )

Table 3. Effect of $0.05 \mathrm{M} \mathrm{NaOH}$ on the stability of RAN

\begin{tabular}{cccc}
\hline Time (min.) & Parent value & \% Remained & Log \% drug remained \\
\hline 0 & 0.012 & 100.0 & 2 \\
15 & 0.008 & 70.8 & 1.85 \\
30 & 0.006 & 52.5 & 1.72 \\
45 & 0.004 & 35.5 & 1.55 \\
60 & 0.003 & 24.0 & 1.38 \\
\hline
\end{tabular}




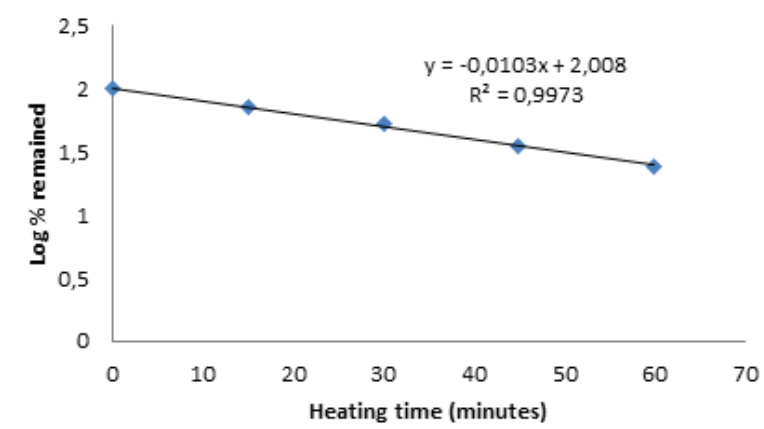

Figure 7. Effect of $0.05 \mathrm{M} \mathrm{NaOH}$ on RAN degradation at $1000 \mathrm{C}$

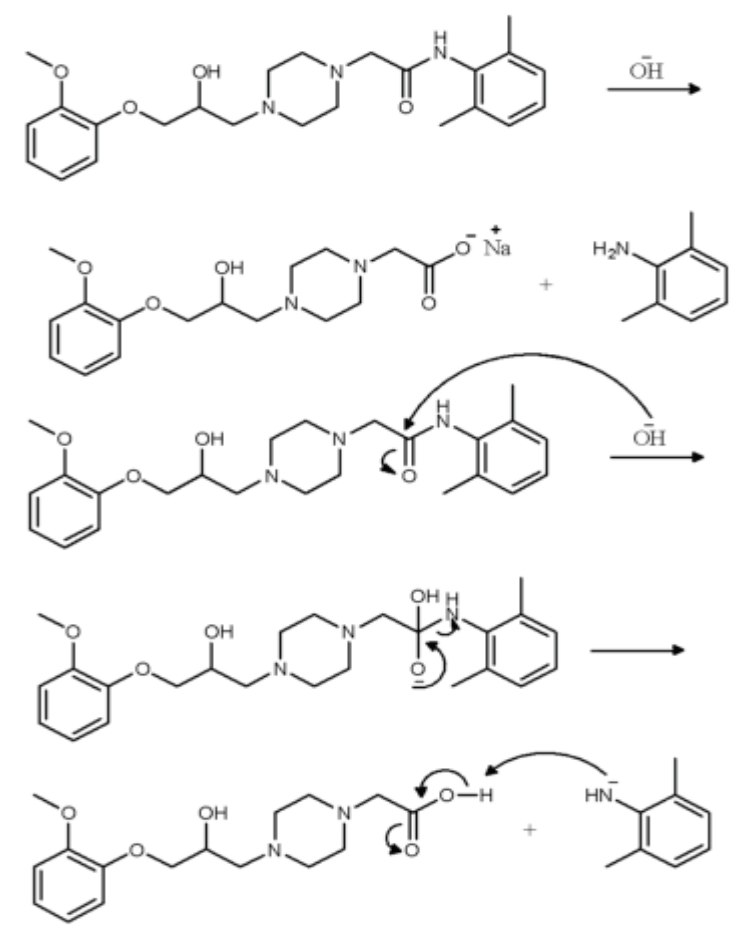

Scheme 1: Proposed pathway of RAN alkaline hydrolysis

\section{Light effect}

RAN solution remained stable upon exposure to sunlight as there was no reduction of drug absorbance or change in the derivative spectrum. This reflected the stability of RAN solution under these conditions.

\section{Conclusion}

The developed methods proved to be simple, rapid, accurate and precise for the determination of RAN in bulk and dosage forms. In addition, the procedure of the developed methods does require neither extraction step nor chemicals and thus can be used for routine quality control analysis of the drug in pharmaceutical industry. The stability indicating properties of the developed methods were successfully proven. Results showed that the drug is unstable under alkaline and heating conditions as it undergoes degradation following the first order kinetics and it was found to be stable in outdoor conditions.

\section{ACKNOWLEDGMENT}

The authors would like to gratitude to technical staff of pharmaceutical chemistry lab, University of Khartoum for their support.

\section{CONFLICT OF INTEREST}

Authors declare that they do not have any conflict of interest

\section{DATA AVAILABILITY}

All the data supporting the findings of the present work are available with the article text.

\section{FINANCIAL SUPPORT}

The authors received no financial support and all the research was self-funded.

\section{AUTHORS CONTRIBUTION}

N.K. conducted the practical work and contributed in the writing the first draft; S.S. wrote the original draft and approved the final draft version; E.G supervised and revised the final draft.

\section{REFERENCES}

1. ICH harmonized tripartite guideline, stability testing of new drug substances and products. 2003; p1-15.

2. Lund W. The pharmaceutical codex. Principals and Practice of Pharmaceutics. 12th Ed. London: The pharmaceutical Press. 1994; p69, 277, 433.

3. Genaro AR, Remington. The science and practice of Pharmacy, 20ted. Philadelphia: Lippincott Williams and Wilkins. 2000; p986. 
4. https://pubchem.ncbi.nlm.nih.gov/compound/Ranolazine

5. Product Information: RANEXA(R) extended-release oral tablets, ranolazine extended-release oral tablets. CV Therapeutics Inc, Palo Alto, CA, 2007.

6. Bidada JP, Gonjari ID, Raut CS, Bhutada CJ. Novel Spectrophotometric method for estimation of Ranolazine in bulk and pharmaceutical dosage form. Der PharmaChemica, 2011; 3 (2): 1-4.

7. Doppa DVS, Konidala SK, Khanabhi S. Development and validation of UV spectroscopic method for the determination of ranolazine in bulk and formulation. Research Journal of Pharmacy and Technology, 2019; 12 (10): 5007-5010.

8. Ganji R, Ramachandran D, Srinivas G, Gowardhane J, Rao P, Srilakshmi V. Development and Validation of Stability Indicating RP-LC Method for Estimation of Ranolazine in Bulk and Its Pharmaceutical Formulations. American Journal of Analytical Chemistry, 2012; 3: 378-384

9. Gade BR, Bandhakavi SR, Satyanarayana MV, Peddi P. Development and validation of stability indicating RP-LC method forestimation of ranalozine in bulk and its pharmaceutical formulations. Journal of Chemical and Pharmaceutical Research, 2015, 7(8):454-461.

10. Khedkar AN, Veer SU, Rakh MS, Rao J R. Stability Indicating Method Development and Validation of Ranolazine Hydrochloride in Bulk and Tablet Dosage Form by HPTLC. International Journal of Pharmaceutical and Clinical Research, 2015; 7(1): 77-83.

11. Sharma A, Prakash D, Singh SK. Development and validation of UV spectrophotometric method for the estimation of ranolazine in bulk drug and pharmaceutical formulation, IJCRGG, 2010; 2 (4): 1945-1948.

12. Sharma T, Si SC, Gowrisankar D. Development and validation of spectrophotometric methods for determination of ranolazine hydrochloride in pharmaceutical dosage forms. Der Pharmacia Lettre, 2014; 6 (4): 420-432.

13. Suresh CV, Sambasiva R, Vidya SG. Development of new visible Spectrophotometric methods for the determination of Ranolazine in pharmaceutical dosage forms. International Journal of Pharmacy and Technology, 2011; 3 (4): 3710-3714.

14. Vetrichelvi S, Aruna A, Niraimathi V, Suresh AJ. Spectrophotometric estimation of ranolazine in bulk and tablet formulation. Int. J. Chem. Sci, 2009; 7(3): 1889-1892.

15. Vetrichelvi S, Aruna A, Niraimathi V, Suresh AJ. Spectrophotometric estimation of ranolazine in tablet dosage form. Asian Journal of Chemistry, 2009; 21 (9): 7443-7445.

16. Uttam B, Animesh G, Amlan KS, Anirbandeep B et al. Determination Of Ranolazine In Human Plasma by LC-MS/MS And Its Application In Bioequivalence Study. Journal of Phar- maceutical and Biomedical Analysis. 2008; 48:1404-1410.

17. Yuan W, Xiaoyan C, Zuoming S, Yong Y, et al. Development And Validation Of A Sensitive LC-MS/MS Assay For Simultaneous Quantitation Of Ranolazine and its three metabolites In Human Plasma. Journal of Chromatography B. 2012:889890, 10-6

18. Rodrigo AS, Thiago B, Pierina SB. Enantioselective analysis of Ranolazine And Desmethyl Ranolazine In Microsomal medium using dispersive liquid-Liquid Microextraction and LC-MS/MS. Bioanalysis. 2013; 5(2):171-83.

19. Limei Z, Hao L, Yao J, Riyang P, et al. Determination of Ranolazine in Human Plasma by Liquid Chromatographic-Tandem Mass Spectrometric Assay. Journal of Chromatographic Science. 2008; 46:697-700.

20. Bhongade B. Diffuse Reflectance Infrared Fourier Transform Spectroscopy (DRIFTS) Application in Pharmaceutical Analysis: Method For Quantification Of Ranolazine in Tablet Dosage Form, Vibrational Spectroscopy, 2017; 93: 52-56.

21. Sreedhara RA, Mohan LA, Anima SD, Mutyala KR. Determination of Ranolazine in Tablet Formulations by HighPerformance Thin-Layer Chromatography-Mass Spectrometry Using Reflectance Scanning Densitometry. Journal of Planar Chromatography. 2016; 29(3):190-194.

22. Priyanka P, Shyam R, Priya P. Research on analytical methods of analysis of Ranolazine: A Review, Himalayan Journal of Health Sciences, 2020; 5 (4): 30-40.

23. Miller JC, Miller JN. 2005. Statistics and chemometrics for analytical chemistry. 5th ed. London, UK. Pearson Education Limited

24. Elimam MM, Shantier SW, GadkariemEA,MohamedMA. Derivative Spectrophotometric Methods for the Analysis and Stability Studies of ColistinSulphate Journal of Chemistry, 2015; Article ID 624316, 5.

25. Daabees HG. Selective differential spectrophotometric methods for determination of Niclosamide and Drotaverine hydrochloride. Analytical Letters 2000; 33(4):639-56

26. Shaza W. Shantier,Elrasheed A. Gadkriem, Mohamed O. Adam and Magdi A. Mohamed. Development of Stability-Indicating Methods for CefquinomeSulphate. International Journal of Biomedical Sciences, 2013; 9 (3): 161-167.

27. Mohammed M. Elimam, Shaza W. Shantier, Elrasheed A. Gadkariem, Magdi A. Mohamed and Zuheir Osman. Stability Studies on Florfenicol using Developed Derivative Spectrophotometric Methods. AnnalesPharmaceutiquesFrancaises, 75: 40-44, 2017.

28. Ruaa Mohamed Akode, Shaza W. Shantier, Magdi A. Mohamed and Elrasheed A. Gadkariem. Simultaneous determination and stability studies on Diaminazinediaceturate and 
Phenazine using developed first derivative spectrophotometry. International Journal of Analytical Chemistry, volume 2017 (2017), article ID 4269587, 6 pages.

29. Sanchez F, Rojas CBO. Recent development in derivative ultra-violet/visible absorption spectrophotometry. Anal Chim Acta 2009; 635:22-44.

30. Shantier SW, Gadkariem EA, Ibrahim KA. A Colorimetric method for the determination of Tobramycin, International Journal of Drug Formulation and research, 2011; 2 (4): 260-272. 